\title{
KNOWELDGE ON EMERGENCY CONTRACEPTION AMONG MEDICAL STUDENTS IN BANGALORE, KARNATAKA
}

N. Ramakrishna Reddy ${ }^{1}$, S.G. Kishore ${ }^{2}$, S Riyaz Basha ${ }^{3}$

\section{HOW TO CITE THIS ARTICLE:}

N. Ramakrishna Reddy, S.G. Kishore, S. Riyaz Basha."Knowledge on Emergency Contraception among Medical Students in Bangalore, Karnataka". Journal of Evolution of Medical and Dental Sciences 2014; Vol. 3, Issue 02, January 13; Page: 369-373, DOI:10.14260/jemds/2014/1835

ABSTRACT: Emergency contraception (EC) refers to methods that women can use to prevent pregnancy after unprotected sexual intercourse, method failure or incorrect use. Unwanted pregnancy followed by unsafe abortion can be avoided by using different contraceptive methods including emergency contraceptives. Inadequate awareness of EC leads to its misuse among the youth, as it may lead to avoidance of condoms which places them at risk for STIs/HIV. The objective of this study is to assess knowledge about emergency contraceptives among M.B.B.S. students. This is a cross-sectional study. Data was collected from Second year medical students of Bangalore Medical College \& Research Institute, Bangalore using Pre-tested semi-structured self-administered questionnaire. The total number of participants was 86 out of this females were $48.8 \%$ (42). 97.6\% (84) participants heard about EC, 50\% (43) said their source of information about EC is health professionals and 58.2\% (50) knew EC to be taken within 72 hours of unprotected sex. There is a lack of complete awareness about EC among studied population. As they are the health care providers in future, their knowledge regarding EC will be useful in educating public especially youth. KEYWORDS: Emergency contraception, Knowledge, Medical students, Karnataka.

INTRODUCTION: Unintended pregnancy poses a major challenge to the reproductive health of young adults in developing countries. Some young women with unintended pregnancies obtain abortions-many of which are performed in unsafe conditions-and others carry their pregnancies to term, incurring risks of morbidity and mortality higher than those for adult women. ${ }^{1}$ Given increasing adolescent sexual activity and decreasing age at first sex in developing countries, ${ }^{2}$ the use of contraceptives to prevent unwanted pregnancy and unsafe abortion is especially important.

Among the various forms of contraception, emergency contraceptives are the only one that can be used after sexual intercourse, offering a second chance to prevent unwanted pregnancy. ${ }^{3}$

Emergency contraception can be used to prevent pregnancy up to 72 hours after unprotected sexual intercourse (post coital use). The pills used in emergency contraception contain the same hormones as ordinary birth control pills, but at a higher dose. Copper-Tintrauterine devices (IUDs) can also be used as emergency contraception when inserted up to 5 days after unprotected sex. They are sometimes called "morning after", but this term is misleading because emergency contraceptives is more than one pill and women can take it up 72 hours after unprotected sex, not just the next morning. Emergency contraception prevents ovulation; fertilization and/or implantation, so it prevents pregnancy from occurring. ${ }^{4}$ There are several reasons why women need emergency contraceptives. The commonest according to recent research is couples did not use a contraceptive method during intercourse $45 \%-67 \%$, failure of a barrier method in $25 \%$ - $48 \%$ including failed coitus interrupts, vomiting of contraceptive pills and rape in $7 \%$ - $14 \%$ of cases. ${ }^{5}$ Emergency contraceptives are regarded as a reasonably effective (85\%) drug in 
the prevention of unwanted pregnancy and have been available since the development of oral contraceptive technologies in the 1960s. However, knowledge and use of emergency contraceptives has been unsatisfactory. It is been observed that while adolescents attitude towards premarital sex are becoming liberal and unintended pregnancies rates are high; their awareness of emergency contraceptives remains poor. ${ }^{5}$ Most adolescents begin their sexual activity without adequate knowledge about sexuality or contraception or protection against STIs/HIV. So we carried out the present study to assess the knowledge of medical students.

AIM AND OBJECTIVE: The objective of this study is to assess knowledge about emergency contraceptives among M.B.B.S students.

MATERIALS AND METHODS: This is a cross-sectional study. Data was collected from Second year medical students of Bangalore Medical College \& Research Institute, Bangalore usingPre-tested semi-structured self-administered questionnaire. Data was analyzed by using Descriptive statistics, viz percentages.

RESULTS AND DISSCUSION: Out of 100 second year M.B.B.S students 86 participated in the study making response rate of $86.0 \%$. The mean age was 20.52 years with the minimum and maximum ages of 19 and 24 years, respectively. Out of 86 participants $51.2 \%$ (44) were male and48.8\% (42) were female. 69.8\% (60) of study participants were Hindus, 24.4\% (21) were Muslims, and the remaining 5.8\% (5) were Christians.

In this present study $97.6 \%$ (84) of students heard about EC, it is in line with Studies conducted in the United States of America (USA) and United Kingdom (UK)in 2008 and 1996 respectively have reported more than $90 \%$ awareness.6,7 A similar study conducted among Jamaican university students in 2002 reported 84\% general awareness of ECs. ${ }^{8,} 9$ However Hiwot Abera, Bosena Tebeje observed in their study, 53\% of university students had heard about EC. 5 Sample of students from a tertiary institution in Trinidad, $63 \%$ of respondents had heard about EC. ${ }^{10}$

The result from this study revealed that 22.1\% (19) of the participants felt that the emergency contraceptives highly effective and $48.8 \%$ (42) felt that it is three -fourth effective method to prevent pregnancy after unprotected sexual intercourse as described in Table-2. Among female college students in Southern Ethiopia 32.9\% felt that the emergency contraceptives highly effective, $19 \%$ felt that it is three -fourth effective method. ${ }^{11}$

Drug compositions in ECPs compared to the regular contraceptives- $6.9 \%$ (6) students said that it is same as in the regular Contraceptives, 73.3\% (63) said that it is same but a high dose in the same hormones, $14 \%$ (12) said that a completely different from the drug of regular contraceptives and remaining 5.8\% (5)said that they don't know. A study done in Southern Ethiopia reported that $20.8 \%$ said that it is same as in the regular Contraceptives, $15.6 \%$ said that it is same but a high dose in the same hormones and $12.7 \%$ said that a completely different from the drug of regular contraceptives. ${ }^{11}$

About 58.2\% (50) have identified the correct timing of administration of pills after unprotected sexual contact which is higher than a study conducted by Hiwot Abera, Bosena Tebeje $48 \% .{ }^{5}$ Health professional's 50\% (43) were most common source of information about Emergency Contraceptives followed by Mass media 29.1\% (25) as described in Table -2. However Hiwot Abera, 
Bosena Tebeje reported that school, health professionals, and friends to be the major sources of information. ${ }^{5}$ The study conducted by B Parey et al observed that sources of information for students were friends/family and media/internet. 10

CONCLUSION: In conclusion, the great potential of emergency contraception to prevent unintended pregnancies and their complications is far from being realized. Lack of adequate knowledge on the method among most of the medical students in this study suggests that the situation is more likely to get worse for the majority of teenagers and young adults with no or low academic attainment. As they are the health care providers in future, their knowledge regarding EC will be useful in educating public especially youth.

\begin{tabular}{|c|c|c|}
\hline Table-1: Socio- demographic characteristics of study participants \\
\hline Characteristics & $\begin{array}{c}\text { Frequency } \\
\text { (N=86) }\end{array}$ & Percent \\
\hline \multicolumn{3}{|c|}{ Age } \\
\hline$<20$ & 45 & 52.3 \\
\hline$>20$ & 41 & 47.7 \\
\hline \multicolumn{3}{|c|}{ Gender } \\
\hline M ale & 44 & 51.2 \\
\hline Female & 42 & 48.8 \\
\hline \multicolumn{3}{|c|}{ Religion } \\
\hline Hindu & 60 & 69.8 \\
\hline Muslim & 21 & 24.4 \\
\hline Christian & 5 & 5.8 \\
\hline
\end{tabular}

Table-2: Knowledge assessment questions regarding Emergency contraceptive

\begin{tabular}{|c|c|c|}
\hline Characteristics & $\begin{array}{c}\text { Frequency } \\
(\mathrm{N}=86)\end{array}$ & Percent \\
\hline \multicolumn{3}{|c|}{ Have you ever heardof EC } \\
\hline Yes & 84 & 97.6 \\
\hline No & 2 & 2.4 \\
\hline \multicolumn{3}{|c|}{ Effectiveness of ECPs } \\
\hline Highly effective (99\%) & 19 & 22.1 \\
\hline Three -fourth (75\%) & 42 & 48.8 \\
\hline Half (50\%) & 5 & 5.8 \\
\hline Below one third (30\%) & 1 & 1.2 \\
\hline Don't now & 19 & 22.1 \\
\hline \multicolumn{3}{|c|}{ Which drugs can be used for EC } \\
\hline Same as in normal contraceptive pills & 6 & 6.9 \\
\hline Same one but stronger & 63 & 73.3 \\
\hline A completely different drug & 12 & 14.0 \\
\hline
\end{tabular}




\begin{tabular}{|l|c|c|}
\hline Do not know & 5 & 5.8 \\
\hline \multicolumn{2}{|c|}{ What is the correct recommended time to take EC } \\
\hline Within 24 hrs. after sex & 20 & 23.2 \\
\hline Within 72 hrs. after sex & 50 & 58.2 \\
\hline After missed period & 14 & 16.2 \\
\hline Don't know Source of information about EC \\
\hline \multicolumn{2}{|c|}{2} & 2.4 \\
\hline Health professional & 43 & 50.0 \\
\hline Mass media & 25 & 29.1 \\
\hline Friends & 7 & 8.1 \\
\hline Both health professionals and mass media & 9 & 10.4 \\
\hline Don't know & 2 & 2.4 \\
\hline
\end{tabular}

\section{REFERENCES:}

1. Harrison KA et al., The influence of maternal age and parity on childbearing with special reference to primigravidae aged 15 years and under, British Journal of Obstetrics and Gynaecology, 1985 5(Suppl.):23-31; and Harrison KA, Obstetric fistulae, unpublished data, Geneva: World Health Organization, 1989.

2. Nnko $S$ and Pool R.Sexual discourse in the contexts of AIDS: dominant themes on adolescent sexuality among primary school pupils in Magu district, Tanzania, Health Transition Review, 1997, 7(Suppl.): 85-90; Adedoyin M and Adegoke AA.Teenage prostitution-child abuse: a survey of Ilorin situation, African Journal of Medicine and Medical Science, 1995, 24(1):27-31; and Oladepo 0 and Brieger WR.AIDS knowledge, attitude and behavior patterns among university students in Ibadan, Nigeria, African Journal of Medicine and Medical Science, 1994, 23(2):119-125.

3. Gold MA, Schein A and Coupey SM.Emergency contraception: a national survey of adolescent health experts, Family Planning Perspectives, 1997, 29(1):15-19; and Barnhart KT and Sondheimer SJ.Emergency contraception, Current Opinion in Obstetrics and Gynecology, 1994, 6(6): 559-563.

4. S. Bhadra, S.C. Tiwari, S. Nandeshwar, R. KAP on Emergency Contraception among Medical \& General Community of Bhopal City Indian Journal of Community Medicine Vol. 30, No. 4, October-December, 2005.

5. Hiwot Abera1, Bosena Tebeje. Knowledge, attitudes, and practices towards emergency contraception among female Jimma University students, Jimma, Southwest Ethiopia; Ethiopian Journal of Reproductive Health May 2009, Volume 3, supplement 1 P 37-43.

6. Vahratian A, Patel DA, Wolff C, Xu X. College students' perceptions of emergency contraception provision. J Women's Health 2008; 17: 103-11.

7. Graham A, Green L, Glasier AF. Teenagers' knowledge of emergency contraception: questionnaire survey in south east Scotland. BMJ 1996; 312: 1567-9.

8. Sorhaindo A, Becker D, Fletcher H, Garcia S, Mitchell S. Exploring knowledge and attitudes about emergency contraceptive pills among university students in Jamaica. A qualitative approach. West Indian Med J 2004; 53: 33-8. 
9. Sorhaindo A, Becker D, Fletcher H, Garcia SG. Emergency contraception among university students in Kingston, Jamaica: a survey of knowledge, attitudes and practices. Contraception 2002; 66: 261-8.

10. B Parey, L Addison et al. Knowledge, Attitude and Practice of Emergency Contraceptive Pills among Tertiary level students in Trinidad: A Cross-sectional Survey. West Indian Med J 2010; 59 (6): 650-55.

11. Alemitu Worku. Knowledge, attitude and practice of emergency contraceptives among female college students in Arba Minch Town, Southern Ethiopia Ethiop. J. Health Dev. 2011;25(3) P 176-83.

\section{AUTHORS:}

1. N. Ramakrishna Reddy

2. S.G. Kishore

3. S.Riyaz Basha

\section{PARTICULARS OF CONTRIBUTORS:}

1. Associate Professor, Department of Community Medicine, Bangalore Medical College \& Research Institute.

2. Assistant Professor, Department of Community Medicine, Bangalore Medical College \& Research Institute.

3. Associate Professor, Department of Community Medicine, Bangalore Medical College \& Research Institute

\section{NAME ADDRESS EMAIL ID OF THE CORRESPONDING AUTHOR:}

Dr.Kishore S.G, Assistant Professor, Department of Community Medicine, Bangalore Medical College \& Research Institute. Email-dr.kishoregowda@gmail.com

Date of Submission: 27/12/2013.

Date of Peer Review: 29/12/2013.

Date of Acceptance: 3/01/2014

Date of Publishing: 09/01/2014 